\title{
A VARIAÇÃo LINGUíSTICA E A FORMAÇÃO DE PROFESSORES/AS DE LÍNGUA PORTUGUESA
}

Adriano de Souza é professor do Curso de Letras - Português e Literaturas de Língua Portuguesa da Universidade Federal do Pampa (Campus Bagé). Tem atuado principalmente nas áreas de Linguística e Práticas de Ensino em Língua Portuguesa.

E-mail: adrianosouza@unipampa.edu.br

Taíse Simioni é professora do Curso de Letras - Português e Literaturas de Língua Portuguesa e do Mestrado Profissional em Ensino de Línguas da Universidade Federal do Pampa (Campus Bagé). Tem experiência na área de Linguística, atuando principalmente nos seguintes temas: fonologia, variação linguística e ensino de línguas. E-mail: taise.simioni@unipampa.edu.br

\section{Resumo}

O presente artigo discute propostas didáticas de alunos/as de um Curso de Letras em que foram mobilizados conhecimentos a respeito da variação linguística. Nossa análise indicou que algumas questões merecem mais atenção nos cursos de formação de professores/as de língua portuguesa. Com base nessas questões, propomos uma sequência didática construída a partir da leitura, da produção textual e da análise linguística.

\begin{abstract}
The present paper discusses didactic proposals from students from a Course in Languages and Literature in which the knowledge over linguistic variation was mobilized. Our analysis has indicated that some issues need more attention in undergraduation courses of teachers of Portuguese. Based on these issues, we propose a didactic sequence which was built from reading, textual production and linguistic analysis.
\end{abstract}

\section{1) Introdução}

O presente artigo tem por objetivo realizar uma discussão sobre a abordagem da variação linguística no ensino a partir de propostas didáticas feitas por alunos/as de um Curso de Letras. Tomando essa discussão como ponto de partida, propomos uma sequência didática que se organiza a partir dos pilares propostos por Geraldi (2004): leitura, produção textual e análise linguística. Ao longo da discussão, chamamos atenção para o fato de que os Cursos de Letras devem propiciar a seus/suas estudantes uma formação sólida em conhecimentos sobre a variação linguística, de maneira que possam ter um olhar sensível e respeitoso às diferentes variedades, ao mesmo tempo em que consigam mobilizar os saberes científicos para realizar uma análise não superficial dos textos.

Para atingir nossos objetivos, organizamos o texto da maneira que segue. Após esta introdução, a segunda seção traz nossa fundamentação teórica, na qual discutimos as contribuições de Geraldi (2004) e dos Parâmetros Curriculares Nacionais para uma "reformulação" do ensino de língua portuguesa, além de mobilizar alguns conceitos importantes para a discussão sobre a construção de uma pedagogia da língua materna que considere a variação linguística como um elemento central. A terceira seção descreve a metodologia adotada em nosso estudo. Na quarta seção, fazemos uma discussão sobre as propostas didáticas elaboradas por alunos/as de um Curso de Letras e apresentamos, a partir dos elementos de fragilidade encontrados, uma proposta de sequência didática. Por fim, a quinta seção traz nossas considerações finais.

\section{2) Fundamentação teórica}

Esta seção está dividida em três partes. Na primeira, fazemos um breve histórico sobre o ensino de língua portuguesa no Brasil, destacando as contribuições de Geraldi 
(2004) e dos Parâmetros Curriculares Nacionais para uma abordagem que toma o texto como objeto de ensino. A segunda parte se dedica a discorrer sobre propostas de ensino que consideram a variação linguística como elemento constitutivo da língua. Na terceira parte, a questão da(s) norma(s) linguística(s) e de suas implicações para o ensino é discutida.

\section{1)Gêneros textuais e ensino de língua portuguesa em dois momentos}

Nas últimas décadas, tem-se observado o crescente número de publicações e pesquisas científicas relacionadas ao campo das práticas de ensino em língua portuguesa de maneira geral e, de maneira específica, às práticas de ensino de linguagem orientadas pela abordagem do texto. Nesse particular, as discussões e propostas que abordam o ensino de língua na perspectiva processual como alternativa a um ensino normativo ganham merecido destaque.

Para entender esse panorama de transição entre modelos e estratégias de ensino e aprendizagem em língua portuguesa, é relevante destacar dois momentos específicos e recentes da, ainda breve, história da disciplina de Língua Portuguesa: 1) a publicação e circulação, em 1984, da obra $O$ texto na sala de aula ${ }^{1}$, organizada por João Wanderley Geraldi, e 2) a publicação dos Parâmetros Curriculares Nacionais (1997/1998).

A obra organizada por Geraldi tem muitos méritos e, não obstante os mais de trinta anos de sua publicação, o livro ainda merece atenta reflexão. É que aí está sistematizada uma agenda político-pedagógica para o ensino de linguagem, através do enfrentamento de temas como a democratização da escola; o ensino de gramática; o ensino de literatura; a variação linguística como componente das aulas de língua e a opção política que se assume - implícita ou explicitamente - ao se deparar com a pergunta: "para que ensinamos o que ensinamos?, e sua correlata: para que as crianças aprendem o que aprendem?" (GERALDI, 2004, p. 40).

É essa indagação de natureza epistemológica que guiará o autor no percurso de discorrer acerca de três concepções de linguagem frequentemente assumidas no domínio das aulas de língua portuguesa (à época, talvez, as duas primeiras fossem mais comuns que a terceira), a saber: a) a linguagem como expressão do pensamento (gramática tradicional); b) a linguagem como instrumento de comunicação (estruturalismo e transformacionalismo) e c) a linguagem como forma de interação (enunciação). A perspectiva assumida pelo autor, discutida no interior da terceira concepção de linguagem, é a que oxigena o debate:

[...] me parece que cabe ao professor de língua portuguesa ter presente que as atividades de ensino deveriam oportunizar aos seus alunos o domínio de outra forma de falar, o dialeto padrão, sem que signifique a depreciação da forma de falar predominante em sua família, em seu grupo social, etc. Isso porque é preciso romper com o bloqueio de acesso

\footnotetext{
${ }^{1}$ Para este trabalho, será cotejada a edição de 2004, referenciada ao final do texto. 
ao poder, e a linguagem é um de seus caminhos. Se ela serve para bloquear - e disso ninguém duvida -, também serve para romper o bloqueio (GERALDI, 2004, p. 44).

Mais recentemente, um bom número de trabalhos tem concluído que o chamado dialeto padrão é antes um instrumento idealizado de cultura que uma língua falada propriamente dita $^{2}$. Como discutiremos mais à frente, trata-se de um modelo ideal de língua, que não corresponde a nenhum dialeto ou a nenhuma variedade empírica da língua, razão pela qual o ensino do chamado dialeto padrão estaria inviabilizado. A questão que a reflexão de Geraldi (2004) acende, todavia, é justamente a necessidade de pensarmos em, por um lado, uma concepção mais ampla e heterogênea de língua a ser ensinada; por outro, em novos paradigmas educacionais, abordagens e metodologias para este trabalho de observação das variedades linguísticas. Aqui entram os Parâmetros Curriculares Nacionais com diretrizes para nortear os currículos das escolas acerca dessa "nova" abordagem.

Os conteúdos passariam, então, a ser articulados em torno de dois eixos básicos: a) o uso da língua oral e escrita e b) a reflexão sobre a língua e a linguagem (BRASIL, 1998, p. 34), razão pela qual o texto, em seu funcionamento, assumiria caráter central nas atividades de língua portuguesa. $\mathrm{O}$ trabalho com unidades da língua (fonema, morfema, sintagma) numa concepção de ensino de língua marcada pela influência estruturalista de estudos linguísticos perderia espaço em razão do trabalho com unidades relativamente estáveis do discurso, os gêneros, na definição clássica bakhtiniana (BAKHTIN, 2010). O objetivo pretendido com esse tipo de ensino traduz-se na ampliação de capacidades de leitura e de escrita a partir da reflexão acerca das práticas sociais da leitura e da escrita. Em outras palavras, trata-se de pensar o ensino de língua portuguesa a partir da noção de letramento e a escola como agência desse fazer (FARACO, 2008; ROJO, 2009; SOARES, 2014).

\section{2) Pedagogia em língua materna}

Noções como "pedagogia da variação linguística" (FARACO, 2008), "sociolinguística educacional" (BORTONI-RICARDO, 2004) e "pedagogia do português brasileiro" (BAGNO, 2011), ente outras, aos poucos têm ganhado espaço nas reflexões sobre o ensino de língua portuguesa. Trata-se, grosso modo, de abordagens teóricocríticas que debatem o ensino de língua materna numa perspectiva mais plural, heterogênea e com sistematicidade - em consonância, portanto, com o caráter heterogêneo da realidade linguística brasileira - e com vistas à superação do olhar monolítico e purista da tradição normativa conservadora.

As três abordagens, não obstante os objetivos de comunicação específicos a cada uma delas, dialogam com afinada destreza. Em comum, fornecem importantes subsídios para formação continuada de professores/as de Letras, especialmente àqueles/as que buscam embrenhar-se nos domínios da variação e da mudança linguísticas, pensados não

\footnotetext{
${ }^{2}$ Por exemplo, Bagno (1999, 2001, 2007) e Faraco (2008). 
apenas como fenômenos sociais, mas também como elementos pertencentes à virtualidade do sistema linguístico.

A noção de competência linguística, tomada de Dell Hymes, de que trata BortoniRicardo (2004), contribui para fundamentar uma proposta de pedagogia em língua portuguesa, a saber:

É papel da escola, portanto, facilitar a ampliação da competência comunicativa dos alunos, permitindo-lhes apropriarem-se dos recursos comunicativos necessários para se desempenharem bem, e com segurança, nas mais distintas tarefas linguísticas. [...]

Ao chegar à escola, a criança, o jovem ou o adulto já são usuários competentes de sua língua materna, mas têm de ampliar a gama de seus recursos comunicativos para poder atender às convenções sociais, que definem o uso linguístico adequado a cada gênero textual, a cada tarefa comunicativa, a cada tipo de interação. [...]

Quando falamos em recursos comunicativos, é bom recordar três parâmetros associados à questão da ampliação desses recursos, que são:

- grau de dependência contextual,

- grau de complexidade do tema abordado e

- familiaridade com a tarefa comunicativa (BORTONI-RICARDO, 2004, p.74-76).

Guiando-se por essa noção de ampliação da competência comunicativa, podemos, com efeito, pensar efetivamente, em espaço escolar, no acesso às variedades cultas e prestigiadas da língua de maneira menos purista e mais voltada à participação discente em práticas sociais de alto nível de complexidade e monitoramento da linguagem oral e escrita. Trata-se, portanto, da inserção do sujeito no domínio da escrita e das práticas especializadas de oralidade. Nos termos de Faraco (2008), tal proposta deveria ultrapassar os limites da disciplina de língua portuguesa não só para propor uma prática de letramento, mas também para construir uma escola letradora:

Essa perspectiva de uma escola letradora - que toma as práticas socioculturais da cultura escrita como um eixo organizador do trabalho escolar - pode vir a pôr a escola disciplinar tradicional sob radicais interrogações, apontando a possibilidade de uma educação transdisciplinar (FARACO, 2008, p. 172).

A primeira proposta de Base Nacional Comum Curricular que veio à tona no conturbado panorama político de 2015 parecia querer desenhar um modelo curricular nessa perspectiva. Não será de todo estranho, contudo, se a proposta final de Base Curricular recuar em relação ao seu escopo interdisciplinar, que acena para o transdisciplinar, sobretudo em face da reação de órgãos de imprensa e da alteração no quadro do executivo federal.

Nesse sentido, cabe comentar acerca de outro intento teórico-crítico, que vem da expressiva elaboração de uma Gramática Pedagógica do Português Brasileiro, do linguista Marcos Bagno. Trata-se, nos termos do autor, "da exposição daquilo que constitui conhecimentos necessários para um trabalho relevante e construtivo de educação linguística" (BAGNO, 2011, p.21). O objetivo é justamente refletir acerca de uma 
pedagogia do português brasileiro, assumindo "a existência de uma norma urbana culta real, radicalmente distinta da norma-padrão clássica" e postulando que "o ensino de língua se faça com base nessa norma urbana culta real" (BAGNO, 2011, p. 21, grifo do autor). Na prática, percebe-se um rigoroso tratamento ao tema da variação linguística, especialmente no tocante aos seus desmembramentos morfossintáticos e fonéticofonológicos.

\section{3) Variação linguística e a questão da(s) norma(s)}

Quando a questão é a variação linguística e sua relação com o ensino, se faz necessário discutir os conceitos de norma culta e norma padrão, conforme se evidenciou na discussão acima. Faraco (2008) define norma culta como "o conjunto de fenômenos linguísticos que ocorrem habitualmente no uso dos falantes letrados em situações mais monitoradas de fala e escrita" (FARACO, 2008, p. 71). Por sua vez, norma padrão é definida pelo mesmo autor como "uma codificação relativamente abstrata, uma baliza extraída do uso real para servir de referência, em sociedades marcadas por acentuada dialetação, a projetos políticos de uniformização linguística" (FARACO, 2008, p. 73).

As definições acima deixam bastante clara uma importante diferença entre os sentidos de norma aqui discutidos. A norma culta diz respeito ao uso (real, concreto) que determinados falantes fazem da língua em certas situações. Já a norma padrão se refere a uma abstração dos fenômenos linguísticos, em busca de uma pretendida uniformização dos usos. A essa distinção cabe a explicação que nos dá Lucchesi (2012) sobre dois adjetivos derivados de "norma": "normal" e "normativo". Segundo Lucchesi, "por NORMAL se entende o que é habitual, costumeiro, tradicional dentro de uma comunidade, já o adjetivo NORMATIVO remete a um sistema ideal de valores que, não raro, é imposto dentro de uma comunidade" (LUCCHESI, 2012, p. 58, grifos do autor). Claramente, a norma culta é constituída por aquilo que é normal na fala de falantes urbanos e letrados em situações de maior monitoramento. Por outro lado, a norma padrão se refere a normativas a serem (ou não) seguidas.

Na discussão sobre a norma culta, Faraco (2008) reconhece os limites desta designação e esclarece que não há a intenção de qualificar como incultas as demais normas, como as normas populares. O autor restringe, então, o uso do qualitativo "culta" à cultura escrita, no sentido de que a norma culta corresponderia ao uso que fazem da língua falantes que têm acesso direto a tal cultura. Faraco, entretanto, faz a ressalva de que tal denominação foi cunhada por falantes da própria norma culta, o que poderia sugerir que, dentro de sua visão de mundo, a norma que rege suas manifestações linguísticas é superior em relação às demais normas. Feita essa discussão, Faraco passa a utilizar a expressão "norma culta/comum/standard". Bagno (2007) também questiona a expressão "norma culta", pelos mesmos motivos apresentados por Faraco (2008), e adota a designação "normas prestigiadas", embora reconheça que é necessário limitar sua interpretação para o sentido de que se trata de normas que são prestigiadas, não de normas que devam, pelo seu valor intrínseco, ser prestigiadas. Fica, assim, evidente que se trata de uma questão complexa o nome pelo qual podemos designar o uso real da língua por falantes urbanos e letrados em 
situações de maior monitoramento. Apesar das limitações e dos problemas recémapontados, seguiremos, neste trabalho, usando a expressão "norma culta".

Dando continuidade à discussão, é importante deixar claro que não há homogeneidade no interior da norma culta (que, nesse sentido, talvez fosse mais adequadamente usada no plural - normas cultas). Faraco (2008) nos dá um exemplo disto ao falar sobre as diferenças entre a norma culta falada e a escrita. Como mostra o autor, os pronomes pessoais oblíquos de terceira pessoa $(o, o s, a, a s)$ praticamente não ocorrem mais na norma culta falada do português brasileiro $(\mathrm{PB})^{3}$. Na norma culta escrita, entretanto, sua existência ainda pode ser atestada.

Com relação ao quase desaparecimento dos pronomes pessoais oblíquos de terceira pessoa da fala no PB, Câmara Jr. (2004) apresenta uma análise que busca explicar o uso de ele como realização da terceira pessoa em qualquer posição sintática (sujeito, objeto direto, objeto indireto e genitivo). Segundo o autor, tal pronome apresenta-se como invariável, do ponto de vista sintático (ele canta, vi ele, dei a ele o papel, vi a casa dele), em função da sua semelhança com os nomes e os pronomes demonstrativos pelo fato de terem flexão de número e gênero, o que não ocorre com os pronomes de primeira e segunda pessoas. Além disso, Câmara Jr. destaca a função anafórica dos pronomes de terceira pessoa, em oposição à função dêitica dos de primeira e segunda pessoas. Por fim, o autor menciona o fato de que uma sílaba sem consoante, como nos pronomes $o, o s, a$, $a s$, é demasiadamente fraca para uma posição também fraca na palavra (pauta pré-tônica, tendo em vista a preferência pela próclise em $\mathrm{PB})^{4}$. $\mathrm{O}$ autor, então, conclui que "há pois uma força de natureza expressiva contra o emprego do pronome regime $o$ e suas variantes do feminino e do plural" (CÂMARA JR., 2004, p. 99). Trazemos, aqui, a discussão feita por Câmara Jr. (2004) para mostrar que uma realização como vi ela ontem, frequentemente estigmatizada e duramente combatida na escola, encontra razões estruturais (no interior do próprio sistema linguístico) para sua existência. Essa discussão tem por finalidade exemplificar o que afirma Faraco (2008): "embora não haja critérios linguísticos capazes de sustentar uma diferenciação qualitativa das normas, essa diferenciação ocorre e é feita por determinados segmentos da sociedade tomando por base valores sociais e políticos" (FARACO, 2008, p. 54). Ou, nas clássicas palavras de Gnerre (1991), “uma variedade linguística 'vale' o que 'valem' na sociedade os seus falantes, isto é, vale como reflexo do poder e da autoridade que eles têm nas relações econômicas e sociais" (GNERRE, 1991, p. 6-7).

Para exemplificar a discussão, tomemos para análise a colocação pronominal. Conforme nos mostra Lucchesi (2012), a norma padrão impõe

\footnotetext{
${ }^{3}$ Sobre a realização do objeto direto anafórico em português brasileiro, sugerimos a leitura de Cyrino (1999) e Dillinger et al. (2002). Ambos os trabalhos tomam para a análise dados do Projeto NURC (Projeto da Norma Linguística Urbana Culta).

${ }^{4}$ Nunes (1996) propõe uma explicação semelhante, no que diz respeito à estrutura silábica, para o uso restrito dos pronomes pessoais oblíquos de terceira pessoa em PB.
} 
um paradigma de colocação dos pronomes-complementos surgido nas profundas mudanças prosódicas que dão ensejo ao português europeu moderno e é absolutamente estranho à pauta prosódica e à estrutura gramatical do português brasileiro (LUCCHESI, 2012, p. 80).

Assim, a norma padrão do $\mathrm{PB}$, que tem o português europeu como fonte de constituição, prevê a ênclise como posição geral para os pronomes oblíquos. Isto, entretanto, contraria a tendência do PB para a próclise ${ }^{5}$. Há, aqui, um evidente exemplo do abismo entre a norma padrão e a norma culta em PB.

Feita, ainda que brevemente, uma distinção entre norma culta e norma padrão, cabe retornar à reflexão sobre as consequências disso para o ensino. Conforme Faraco (2008), o abismo que separa as duas normas ${ }^{6}$ torna o ensino da norma padrão inócuo. Segundo o autor, a norma padrão está na base da perniciosa cultura do erro que reina entre nós. Assim, Faraco defende uma pedagogia da variação linguística que, entre outras questões, "localize adequadamente os fatos da norma culta/comum/standard no quadro amplo da variação e no contexto das práticas sociais que a pressupõem" e "abandone criticamente o cultivo da norma-padrão" (FARACO, 2008, p. 180). Faraco (2008) faz menção aos contínuos propostos por Bortoni-Ricardo $(2004$, 2005) e localiza as variedades prestigiadas, na denominação de Bagno (2007), no entrecruzamento do polo urbano (no continuum rural-urbano) com o polo do letramento (no continuum oralidade-letramento). Quanto à monitoração estilística, o autor destaca o fato de que essas variedades se movimentam entre os diferentes estilos, dos mais aos menos monitorados, como ocorre em todas as variedades. Para deixar esta questão mais clara, discorreremos, ainda que brevemente, sobre os contínuos propostos por BortoniRicardo. Segundo Faraco (2008), uma visão em continuum "permite melhor apreender a distribuição social das variedades (e, acima de tudo, a dinâmica que rege a intensa interrelação entre elas) e os pontos em que há estigmatização de formas" (FARACO, 2008, p. 168).

Bortoni-Ricardo $(2004$, 2005) busca, a partir da proposição dos três contínuos, "apreender de forma mais precisa a complexa situação sociolinguística do português brasileiro" (BORTONI-RICARDO, 2005, p. 40). Assim, o continuum rural-urbano tem, em um polo, as regiões rurais mais isoladas e, no outro, a variedade urbana culta. Ao longo deste continuum, é possível localizar dois tipos de regras: as descontínuas e as graduais. As primeiras dizem respeito às regras que caracterizam as variedades rurais $\mathrm{e}$ as variedades sociais mais isoladas. Tais regras sofrem forte estigmatização. Podemos tomar como exemplo o rotacismo, pelo qual há substituição de "l" por "r" em uma palavra, como nas realizações "brusa" e "pranta”, por exemplo. Já as regras graduais não

\footnotetext{
${ }^{5}$ Cyrino (1996), no contexto de análise da realização do objeto anafórico, faz um estudo diacrônico da passagem da ênclise para a próclise em PB.

${ }^{6}$ Faraco (2008) e Lucchesi (2012) fazem um histórico sobre a constituição da norma padrão no Brasil, mostrando que, no século XIX, o português de Portugal, e não a norma culta brasileira, foi tomado como parâmetro para sua formação. Bagno (2003) observa, nesse processo, uma tentativa das elites locais de construção de um projeto europeizante de civilização, baseado na construção de uma identidade linguística que em nada lembrasse a língua praticada nos trópicos.
} 
distinguem as variedades linguísticas, uma vez que estão presentes na fala da maioria dos falantes. Sua aplicação dependerá do nível de formalidade do evento comunicativo, ou, como veremos, da localização desse no continuum de monitoração estilística. Um exemplo de regra gradual pode ser a monotongação do ditongo "ow", como nas realizações "oro" e "andô", para "ouro" e "andou", respectivamente.

Quanto ao continuum de oralidade-letramento, este vai dos eventos orais aos eventos de letramento. Como explica Bortoni-Ricardo (2004), no polo oral estarão os eventos que não sofrem influência direta da escrita, enquanto no polo do letramento estarão localizados os eventos em que ocorre a mediação da língua escrita. BortoniRicardo (2005) justifica a proposição deste continuum pelo fato de que

a inserção do falante em uma cultura predominantemente oral ou predominantemente letrada tem consequências decisivas para sua apropriação de recursos comunicativos próprios das modalidades oral e escrita e dos gêneros discursivos (BORTONIRICARDO, 2005, p. 51).

Por fim, temos o continuum de monitoração estilística. Como explica BortoniRicardo (2005), o nível de monitoração do falante dependerá da atenção e do planejamento envolvidos na interação. Como destaca a autora, todos os falantes alternam seus estilos, mas os recursos necessários para isso estarão relacionados com os papéis sociais que assumem. Bortoni-Ricardo (2004) esclarece que a monitoração estilística é influenciada por três fatores: o ambiente, o interlocutor e o tópico da conversa. A interação entre eles implicará uma maior ou menor monitoração do falante, no sentido de que, por exemplo, o interlocutor pode ser o mesmo, mas o nível de monitoração será diferente a depender do tópico da conversa (um assunto mais ou menos sério, por exemplo).

Nessa discussão sobre a variação linguística e sua abordagem no ensino, cabe mencionar a maneira como a questão aparece nos livros didáticos de língua portuguesa. González (2015) e Lima (2014) apontam que, em função das exigências do Programa Nacional do Livro Didático (PNLD) ${ }^{7}$, a variação linguística está presente nos livros didáticos atuais. Essa presença, entretanto, ocorre de maneira superficial, como se este assunto fosse apenas mais um conteúdo, entre tantos outros, o que leva, em muitos casos, à mera inserção de um capítulo dedicado à variação a fim de atender às exigências do PNLD. González (2015) também destaca o predomínio da variação no nível lexical ${ }^{8}$ e, quanto ao tipo, da variação diacrônica e diatópica. Conforme discute o autor, tal cenário leva a um distanciamento da variação em relação aos/às alunos/as, invisibilizando sua presença no dia a dia dos/as discentes. Dionisio (2005), por sua vez, analisa algumas questões de livros didáticos em que é solicitado ao/à aluno/a que passe determinado texto para a norma padrão. Segundo a autora, tais questões não respeitam a natureza (gênero, público-alvo, objetivos) do texto. Como alerta Dionisio,

\footnotetext{
${ }^{7}$ Para um histórico sobre o PNLD, sugerimos a leitura de Batista (2003).

${ }^{8}$ Como alerta Bagno (2007), "os livros didáticos, infelizmente, ainda não se deram conta da importância da variação morfossintática e das consequências dela para uma educação em língua materna eficiente e formadora de cidadãos" (BAGNO, 2007, p. 134).
} 
se a intenção é incentivar o aluno a reescrever, fazendo a transposição da linguagem informal para a formal, é necessário propiciar uma situação comunicativa em que o emprego da linguagem formal seja exigido (DIONISIO, 2005, p. 86).

\section{3) Metodologia}

Os dados da pesquisa foram coletados a partir de uma atividade diagnóstica realizada no componente curricular "Sociolinguística e Ensino". Participaram da atividade doze estudantes, regularmente matriculados no Curso de Licenciatura em Letras - Língua Portuguesa e Literatura de uma Universidade Federal do interior do estado do Rio Grande do Sul. Pode-se dizer que todos/as os/as estudantes estavam, no mínimo, no segundo ano do referido Curso superior, fato que significa ter conhecido, com desempenho satisfatório, as principais abordagens da linguística moderna e seus objetos teóricos, além das leituras de formação do cânone da literatura ocidental.

A atividade ocorreu em agosto de 2016 e, na ocasião, foi entregue uma folha com a letra da canção "Cuitelinho" e as seguintes informações:

"Cuitelinho" é uma música brasileira com origem no folclore do Pantanal de Mato Grosso. Considerada uma das mais lindas músicas do cancioneiro popular brasileiro, Cuitelinho (denominação regional para Beija-flor) conta, à maneira do povo, uma pequena história de saudade, que pode ser interpretada como a saudade de um soldado brasileiro que lutou na Guerra do Paraguai. A letra foi recolhida por Paulo Vanzolini durante uma pescaria, e interpretada por grandes nomes da música popular brasileira, como Nara Leão, Milton Nascimento, Renato Teixeira e os sertanejos Pena Branca e Xavantinho. Foi composta originalmente por volta de 1932 por Bento Costa. (Fonte:

https://pt.wikipedia.org/wiki/Cuitelinho - acesso em 08/05/2016).

Imagine que você irá trabalhar com a letra de música "Cuitelinho" em sala de aula e proponha uma atividade que explore a construção de sentido do texto, não se esqueça de selecionar um público-alvo ao qual sua atividade será apresentada.

Letra da música:

Cheguei na beira do porto onde as ondas se 'espaia'

As 'garça' dá meia-volta e senta na beira da praia

E o cuitelinho não gosta, que o botão de rosa caia

Ai quando eu vim da minha terra despedir da 'parentaia'

Eu entrei no Mato Grosso bem em terras Paraguaias

lá tinha revolução, enfrentei forte 'bataia'

A tua saudade corta como aço de 'navaia' o coração fica 'afrito', bate uma e a outra 'faia' E o 'zoio' se enchem d'água que até a vista se 'atrapaia'

A tua saudade corta como aço de 'navaia' o coração fica 'afrito', bate uma e a outra 'faia' E o 'zoio' se enchem d'água que até a vista se 'atrapaia' 
Após a leitura da letra da canção, passou-se à escuta da música, primeiro na voz de Nara Leão, depois na voz de Milton Nascimento. O objetivo fundamental desta atividade residia em elaborar um diagnóstico a respeito de como os/as estudantes compreendiam a articulação entre ensino de língua e a abordagem da sociolinguística. Cabe mencionar que a noção de variação linguística e os aportes da abordagem sociolinguística já haviam servido à reflexão discente em outros componentes curriculares. A escolha desse texto para objeto de reflexão se deu por dois motivos principais: 1) o interesse de provocar indiretamente a reflexão acerca da variação linguística e 2) que a abordagem da atividade levasse em conta um movimento do uso da língua (condições de produção) para reflexão sobre a língua (prática epilinguística). Para propor esta atividade, dispúnhamos, como principal referência paradidática, da análise de Bagno (2006) em A língua de Eulália, obra em que a personagem professora Irene utiliza a mesma letra de música para explicar às jovens universitárias Sílvia, Emília e Vera alguns fenômenos do português não padrão, dos quais merecem destaque, no plano morfossintático, a questão das marcas redundantes de plural e a questão da simplificação das conjugações verbais ${ }^{9}$ e, no plano fonéticofonológico, a transformação de 'lh' em 'i' ${ }^{10}$. Os resultados serão discutidos a seguir.

\section{4) Discussão}

Nesta seção apresentaremos uma análise acerca da atividade diagnóstica realizada conforme exposto na seção de metodologia. Trataremos, inicialmente, de apontar os elementos mais evidentes na leitura das doze propostas de atividade, destacando alguns aspectos positivos e alguns aspectos insuficientes, do ponto de vista da adequação ao enunciado proposto. Feito esse relato mais geral, dividiremos os dados coletados nas propostas em dois grandes grupos para, em seguida, discutirmos algumas considerações preliminares geradas pelo estudo. Para concluir a seção, apresentaremos uma sugestão de prática de ensino em língua portuguesa, buscando contemplar os elementos teóricometodológicos discutidos ao longo do artigo.

Considerando a amplitude do enunciado proposto, qual seja, propor uma atividade atenta à construção de sentido de um texto de índole estética, realizamos a leitura das respostas procurando observar as escolhas pedagógicas, psicológicas e linguísticas (Cf. SCHNEUWLY et al. 2004, p. 91-92) de cada estudante. Destacamos, quanto às escolhas psicológicas, que todas as respostas mostraram-se sensíveis à representação da situação de comunicação, da qual emerge o gênero em questão. Percebemos que, praticamente, todas as respostas propuseram, inicialmente, a escuta da canção, seguida de leitura e

\footnotetext{
${ }^{9}$ São muitos os estudos sociolinguísticos sobre a variação na concordância de número em PB. A título de exemplificação, citamos Naro e Scherre (2003). Vieira (2008), por sua vez, faz uma discussão sobre a concordância verbal variável em PB em sua relação com o ensino.

${ }^{10}$ Estudos sociolinguísticos sobre a realização da lateral palatal são menos frequentes, quando comparados àqueles sobre a concordância de número em PB. Citamos Brandão (2007) como exemplo de pesquisa que observa a realização variável da lateral palatal.
} 
discussão acerca da temática. Mesmo que a maioria das respostas não tenha especificado objetivamente em que termos proporia uma discussão sobre o texto, é possível suspeitar que os/as estudantes consideram a noção de que uma língua se adapta às diferentes situações de comunicação, ao passo que as cria e recria. Observamos, entretanto, que poucas foram as respostas que se ocuparam de pensar uma sequência de atividades regradas que envolvessem a produção e circulação de mais de um texto, tendo, a maioria das propostas, gravitado em torno de gêneros menos monitorados.

Do ponto de vista das escolhas pedagógicas, destacamos o fato de a maioria das respostas (onze de doze) ter contemplado uma relação de pertinência entre a abordagem e o público-alvo. Entretanto, há que se destacar o fato de nenhuma proposta ter pensado na avaliação da própria proposta de atividade, o que pode estar demonstrando certa insegurança em relação aos aspectos a serem explorados como objeto de ensino da atividade. Considerando que a tarefa pedagógica se efetiva no planejamento, na execução e na avaliação, o terceiro elemento deste fazer não deveria ser negligenciado, sob pena de colocarmos os dois primeiros a perder.

Quanto às escolhas linguísticas das abordagens, a análise das respostas levounos a concluir que as propostas aproximavam-se em torno de dois princípios: ou consideravam o texto ("Cuitelinho") como um pretexto para discutir temáticas afins, como "preconceito" ou "variação linguística"; ou as respostas orientavam a reescrita do texto com substituição lexical por sinônimos. Com relação ao primeiro princípio, foi possível perceber que o resultado é um discurso genérico, que não retorna ao texto na busca de evidências concretas. Como alerta Bopp da Silva (2015),

sem o conhecimento da lógica da variação e de toda a sua amplitude, o professor não compreenderá o fenômeno variável e apenas substituirá o discurso do purismo linguístico pelo discurso do politicamente correto, porque assim foi doutrinado (BOPP DA SILVA, 2015, p. 153).

Quanto ao segundo princípio, cabe retornar à crítica feita por Dionisio (2005): as propostas de reescrita não levaram em consideração a noção de gênero e, portanto, desconsideraram o enunciador, seu interlocutor pretendido, os objetivos do texto, seu conteúdo. Um dos alunos propõe a reescrita do texto "com palavras usuais do dia a dia de cada um sem que seja perdida a essência do texto". Perguntamo-nos em que medida isso seria possível. Os excertos abaixo ilustram, respectivamente, o primeiro e o segundo princípio.

(1)

Explicaria sobre a variação linguística e que [isto] acontece por diversos fatores.

(2)

Em seguida, [sugiro] pedir aos alunos que seja construída uma nova versão, porém utilizando a variação deles (alunos), explicando o que entenderem do texto. 
Feitas essas observações iniciais, passamos a desenvolver algumas considerações no sentido de especular em torno da noção de variação sugerida pelas atividades. Ao analisar as propostas apresentadas pelos/as alunos/as, foi possível perceber que a maioria restringiu-se à variação no nível lexical. Os excertos abaixo ilustram esta afirmação.

(3)

Propor a reescrita com palavras usuais do dia a dia de cada um sem que seja perdida a essência da letra.

(4)

Após a leitura da letra da música, propor aos alunos uma discussão sobre o tema da música, destacando as variações existentes e questionando-os sobre a origem dessas palavras, se já ouviram falar, se conhecem de outra forma, etc.

Como é possível observar, em (3), o aluno refere-se a "palavras usuais" e, em (4), é feita menção a "origem dessas palavras". Esses excertos, então, ilustram o fato de que muitos/as alunos/as parecem ter reconhecido como aspectos variáveis no texto apenas a presença de palavras que não são comuns em suas próprias variedades. Inspecionando o texto em busca de palavras que pudessem se encaixar na variação que ocorre no nível lexical, encontramos apenas a palavra "cuitelinho", uma vez que todas as demais, por suposição, fazem parte do repertório linguístico dos alunos. Voltaremos a essa questão adiante.

Quanto ao tipo de variação mais presente nas propostas feitas pelos/as alunos/as, encontramos a variação regional, como mostram os excertos (5) e (6).

(5)

Após, seria proposta uma atividade onde cada aluno reescreveria tal letra, substituindo as palavras que sofreram variação, por termos usados pelos falantes de sua região, ou que eles propriamente fazem uso.

(6)

Depois de ouvir a canção, instigar os alunos a identificar as expressões que não são tão usuais no dialeto gaúcho.

O excerto (5) indica que, para este aluno, a letra da canção foi composta por alguém de outra região, diferente daquela de que proviriam os/as estudantes-alvo de sua atividade, embora não haja uma definição sobre a outra região. Aqui, mais uma vez, a presença da expressão "termos" nos remete à ideia de que a variação no texto objeto de análise dos/as alunos/as se restringe àquela que ocorre no plano lexical. Com relação ao excerto (6), o aluno localiza a letra da canção como originária de uma região do Brasil que não corresponde ao Rio Grande do Sul. Voltando ao texto, não conseguimos localizar expressões que, caracteristicamente, não seriam usadas na variedade gaúcha, com exceção, talvez, de "cuitelinho". 
Como mencionamos anteriormente, os livros didáticos, ao abordarem a variação linguística, colocam seu foco na variação regional e no nível lexical. Não nos parece que seja coincidência o fato de os/as alunos/as cujas propostas analisamos aqui façam o mesmo. É possível que, neste momento, estes/as alunos/as ainda estejam muito influenciados/as pela maneira como a variação foi discutida ao longo de sua formação na Educação Básica, partindo do pressuposto de que o livro didático teve uma presença marcante durante tal formação. Observar isso nos leva a defender a necessidade de uma formação nos Cursos de Letras que oportunize aos/às alunos/as uma discussão qualificada sobre a variação linguística e sobre suas implicações para o ensino de línguas.

Com exceção de dois alunos, nenhum/a outro/a fez menção à variação no nível morfossintático e no nível fonético-fonológico que podemos observar na letra da canção sob análise. Como foi mencionado anteriormente, no nível morfossintático, temos a ausência da marcação de concordância nominal e verbal no texto e, no nível fonéticofonológico, encontramos uma variante desprestigiada da lateral palatal. O trecho "as onda se espaia" traz um exemplo dos três fenômenos. Além disso, o texto mostra, também, o rotacismo na palavra "afrito". Ao não mencionarem a presença de tais fenômenos na letra da canção, os/as alunos/as, consequentemente, não fazem a discussão sobre a distinção entre os traços graduais (neste caso, a falta de marcação da concordância nominal e verbal) e os traços descontínuos (aqui, a realização estigmatizada da lateral palatal e o rotacismo). Tal distinção é essencial, uma vez que temos aqui fenômenos com implicações diferentes no que diz respeito aos contínuos propostos por Bortoni-Ricardo (2004, 2005). Enquanto a ausência da marcação de concordância nos leva a enquadrar a letra da canção no polo menos monitorado do contínuo de monitoração, a realização estigmatizada da lateral palatal e o rotacismo têm pertinência para a observação de outro contínuo: o de urbanização, o que nos permite posicionar o texto como pertencente a uma variedade rural.

É neste momento que retomamos a discussão anterior, sobre a predominância da variação no nível lexical nas propostas dos/as alunos/as. Conforme já mencionamos, no nível lexical, a única palavra que, em princípio, não faria parte da variedade dos/as alunos/as cujas propostas estão sendo analisadas e dos/as alunos/as para quem tais propostas foram planejadas é "cuitelinho". A partir disso, apontamos dois possíveis caminhos para tentar compreender essa aparente incoerência. Um caminho aponta para o fato de que, talvez, a presença do rotacismo e da realização estigmatizada da lateral palatal tenha feito com que os alunos pressupusessem que deveria haver palavras representativas da variedade rural, sem que fizessem um exame mais atento no texto a ponto de perceberem que essa pressuposição não se confirma. O outro caminho indica na direção de que é possível que os alunos tenham se referido a "palavras" com o intuito de se referir às suas diferentes formas de realização, não a diferentes palavras para exprimir o mesmo referente. Tanto um caminho quanto o outro nos levam, novamente, a insistir na ideia de que os Cursos de Letras precisam propiciar a seus/suas alunos/as uma formação que lhes permita: (i) olhar para um texto e buscar nele as evidências linguísticas que nos autorizam a fazer 
determinadas afirmações e (ii) expressar de maneira clara e adequada sua compreensão sobre os fenômenos linguísticos que analisarem.

Frente a esse quadro, convém dirigirmos a reflexão teórica ao encontro de uma prática de ensino. Para tanto, nos serviremos dos aportes procedimentais e metodológicos de uma sequência didática (Cf. SCHNEUWLY et al. 2004, p. 81-108) com o gênero verbete de enciclopédia. Pretendemos, com esta prática, instigar o/a leitor/a a refletir sobre a pertinência e a possibilidade de se desenvolver um ensino de língua portuguesa que seja: 1) pautado/motivado/orientado pela ampliação das competências comunicativas dos/as estudantes, o que implica pensar em metodologias de ensino que possibilitem inserir o/a estudante em atividades de letramento condizentes à complexidade de práticas sociais da cultura letrada; 2) do uso da língua para reflexão sobre a língua, através de atividades de leitura, do trabalho regrado com a oralidade e da escrita, recepção e circulação de gêneros públicos, formais e, portanto, monitorados; 3) também espaço de análise linguística (reflexão sobre a linguagem), por meio de instrumentos normativos (gramáticas, dicionários e - por que não? - livros didáticos), que além de permitirem a compreensão do funcionamento interno da língua, apresentem a descrição da variedade culta estudada, contemplando sua maleabilidade funcional ${ }^{11}$.

Sendo assim, dividimos nossa abordagem em três etapas, as quais correspondem ao planejamento, à execução e à avaliação da atividade pedagógica. Cada momento desse fazer divide-se, por sua vez, em etapas específicas que serão desenvolvidas em conformidade à escolha didático-metodológica do/a professor/a. Em nosso caso, optamos por elaborar uma sequência didática para escrita, motivada pela letra de música "Cuitelinho".

Convém destacar que a atividade foi pensada com vistas a ser desenvolvida em uma turma de ensino médio da Educação Básica. Cabe salientar, entretanto, que esse auditório social projetado foi elaborado hipoteticamente, com base nos objetivos de aprendizagem típicos para esse público-alvo. Não há qualquer garantia, devemos advertir, de que este planejamento funcione de fato se for aplicado mecanicamente num contexto em que são ignoradas as especificidades histórico-sociais da prática educativa. Por isso, reafirmamos que toda proposta de ensino, enquanto proposta, é um vir a ser que se caracteriza fundamentalmente por seu inacabamento, razão pela qual deve ser completada/complementada por quem a ela se dedique.

Em termos de planejamento, parece oportuno iniciar por uma detida reflexão que nos leve a elaborar um quadro de "conteúdos", um mapa dos objetos de ensino possíveis e passíveis de serem deslindados pela leitura e escuta da letra de música "Cuitelinho", sem perder de vista o público-alvo de nossa atividade. Neste sentido, é importante ter

\footnotetext{
${ }^{11}$ Cf. Faraco (2008), "o estudo de conteúdos gramaticais faz sentido quando feito de forma contextualizada e funcional (i.e., subordinado às atividades que visam o domínio das práticas de fala e escrita). Além disso, seu estudo deve ser feito de modo a destacar a flexibilidade estrutural da língua e a consequente riqueza expressiva à disposição dos falantes: nenhuma língua é um conjunto rígido de expressões. Sua organização estrutural se caracteriza - sendo, como é, produto e processo histórico - como um vasto universo de variedades expressivas, de formas alternativas, o que implica antes escolha que submissão" (p. 162).
} 
alguma clareza a respeito da tipologia dos conteúdos, os quais serão divididos em conteúdos conceituais, conteúdos procedimentais e conteúdos atitudinais ${ }^{12}$; em outras palavras, estamos pensando que os conteúdos a serem trabalhados dizem respeito à construção de diferentes estruturas cognitivas, referindo-se à dimensão teórica/epistemológica (conteúdos conceituais), pragmática/prática (conteúdos procedimentais) e ética/política (conteúdos atitudinais) do conhecimento.

Considerando que uma sequência didática é um procedimento que possibilita ao/à estudante dominar um determinado gênero de texto, propomos a elaboração de um verbete de enciclopédia, tendo como objetivo de comunicação descrever e analisar a letra de música "Cuitelinho". Sendo assim, elaboramos o seguinte quadro de conteúdos a serem explorados em nossa proposta de atividade:

\begin{tabular}{|c|c|c|}
\hline $\begin{array}{l}\text { Conteúdos conceituais: } o \text { que } \\
\text { se deve saber? }\end{array}$ & $\begin{array}{l}\text { Conteúdos procedimentais: } o \\
\text { que se deve saber fazer? }\end{array}$ & $\begin{array}{l}\text { Conteúdos atitudinais: } \\
\text { como se deve ser? }\end{array}$ \\
\hline $\begin{array}{l}\text { Trata-se de pensar/avaliar } \\
\text { que conhecimentos sobre a } \\
\text { língua se fazem necessários } \\
\text { para cumprir efetivamente a } \\
\text { tarefa comunicativa. Por } \\
\text { exemplo: } \\
\text { Domínio das convenções } \\
\text { do texto escrito: } \\
\text { adequação ao gênero } \\
\text { verbete de enciclopédia: } \\
\text { compreensão da situação } \\
\text { de }\end{array}$ & $\begin{array}{l}\text { Trata-se de pensar/avaliar a } \\
\text { ampliação dos recursos } \\
\text { comunicativos na elaboração } \\
\text { do verbete de enciclopédia. } \\
\text { Para tanto, o/a professor/a } \\
\text { poderá considerar três } \\
\text { parâmetros } \\
\text { (Cf. BORTONIRICARDO, } \\
\text { 2004, p. 75- } \\
\text { 76): } \\
\text { Grau de dependência } \\
\text { contextual; (o texto } \\
\text { elaborado possui }\end{array}$ & $\begin{array}{l}\text { Trata-se de pensar/avaliar se } \\
\text { a tarefa comunicativa } \\
\text { contribuiu para: } \\
\text { - Identificação da variação } \\
\text { comoremento } \\
\text { constituinte da realidade } \\
\text { linguística brasileira; } \\
\text { (acredita-se que dominar } \\
\text { tecnicamente a análise } \\
\text { tenha o serviço de } \\
\text { sensibilizar o/a estudante } \\
\text { para o fato da }\end{array}$ \\
\hline
\end{tabular}

${ }^{12}$ Cf. Zabala (1998, p. 30-31), esta classificação corresponde respectivamente às perguntas "o que se deve saber?" [conteúdos conceituais]; "o que se deve saber fazer?" [conteúdos procedimentais] e "como se deve ser?" [conteúdos atitudinais]. 


\begin{tabular}{|c|c|c|}
\hline $\begin{array}{l}\text { - comunicação; escolha } \\
\text { adequada dos } \\
\text { conteúdos; } \\
\text { planejamento e } \\
\text { realização do texto. } \\
\text { Análise linguística: } \\
\text { identificação } \\
\text { léxicogramatical } \\
\text { subjacente ao texto que } \\
\text { subsidiará o verbete. }\end{array}$ & 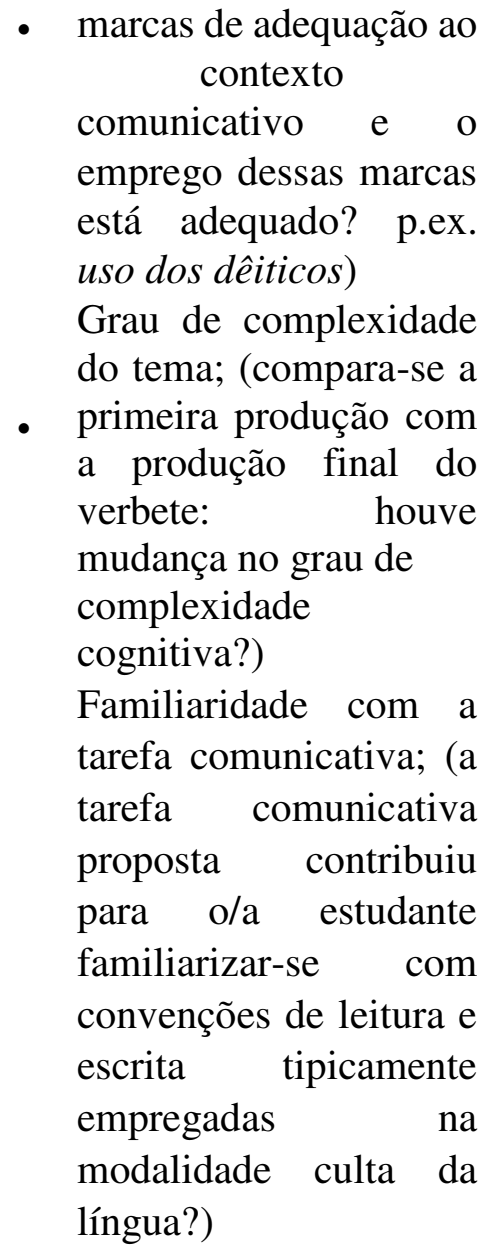 & $\begin{array}{l}\text { - } \text { diferença como } \\
\text { constituinte dessa } \\
\text { realidade) } \\
\text { Conscientização mais } \\
\text { ampla acerca da noção } \\
\text { de erro de } \\
\text { português/erro } \\
\text { linguístico, preconceito } \\
\text { linguístico/ preconceito } \\
\text { social; } \\
\text { adequação/inadequação } \\
\text { ao contexto } \\
\text { comunicativo. }\end{array}$ \\
\hline
\end{tabular}

Nota-se que o quadro dos conteúdos, correspondente à etapa do planejamento da atividade, será um importante aliado na etapa da avaliação, pois já temos aí um arrazoado de elementos descritos que servirão de base para acompanhar e intervir no processo de ensino-aprendizagem. Destaca-se, com efeito, que o procedimento de sequência didática privilegia a avaliação formativa, à medida que permite observar o processo de ampliação dos recursos comunicativos. Além disso, o procedimento também possibilita a avaliação de tipo somatório, à medida que considera a produção inicial e a parametriza com a produção final.

Uma vez que os elementos, as variáveis e as dimensões do objeto de ensino estejam sistematizados, há que se pensar na apresentação da situação de comunicação, na qual os/as estudantes deverão atuar através do verbete. Trata-se, ainda, do planejamento da atividade e corresponde à apresentação de um problema de comunicação bem definido que atente às questões: a) qual é o gênero a ser abordado?

b) a quem se dirigirá a produção? c) que suporte assumirá a produção? d) quem participará da produção?. Aqui, o/a professor/a deverá ter noção suficiente acerca do gênero a ser trabalhado; convém consultar um dicionário de gêneros textuais (p.ex. COSTA, 2014) ou um dicionário de língua portuguesa para saber tecnicamente o que é um verbete de enciclopédia. O dicionário que consultamos apresenta a seguinte definição: 
VERBETE (v. ARTigo, CHAMAdA, ENTRADA, RUBRICA, TÍtUlO): em lexicografia, cada entrada (v.) de dicionário (v.), enciclopédia (v.), glossário (v.), etc. constitui um verbete. Cada verbete se caracteriza pelo conjunto de acepções, das definições, exemplos e outras informações específicas. Predomina a linguagem referencial das definições, feita de maneira objetiva, com conferência a vários campos do conhecimento, as chamadas rubricas (v.). (COSTA, 2014, p. 224).

A situação de comunicação a ser apresentada à turma poderá ser representada através da seguinte formulação: a turma deverá elaborar um verbete de enciclopédia para "Cuitelinho" (letra de música) para ser publicado em ambiente virtual ${ }^{13}$. Esse verbete será dividido em rubricas, pelas quais ficarão responsáveis os grupos.

Do ponto de vista da execução da atividade, convém partir pela escuta silenciosa da música por diferentes intérpretes. O/a professor/a poderá, aqui, levar elementos biográficos acerca dos intérpretes e do compositor, bem como dissertar sobre suas obras, com vistas, caso necessário, a aproximar a sensibilidade dos/as estudantes da atividade proposta. Metodologicamente, convém dividir a turma em grupos, e propor uma pesquisa de cunho histórico, que possibilite situar o/a intérprete no quadro maior da Música Popular Brasileira. Seria relevante, neste momento, manusear, junto aos grupos, uma enciclopédia de música popular, por exemplo. Assim, a turma poderá ter maior familiaridade com o suporte e com o gênero. Igualmente relevante será se a turma puder dedicar-se a uma consulta à internet, com vistas a traçar diferenças e similaridades entre os suportes impresso e digital.

Feito esse importante percurso de sensibilização, pode-se entrar na análise da letra de música. Para tanto, os grupos já deverão estar cientes de que o verbete a ser elaborado deverá dar conta dos seguintes elementos: Rubrica 1: contextualizar a letra da canção no quadro maior da história da Música Popular Brasileira; Rubrica 2: apresentar a acepção regional do item lexical "cuitelinho" e apresentar definição científica da biologia, p.ex.; Rubrica 3: descrever a gramática subjacente à letra da música, especialmente do ponto de vista morfossintático e fonético-fonológico, comparando as regras empregadas na letra com usos orais e escritos colhidos de textos não poéticos; Rubrica 4: análise dos traços graduais e descontínuos da letra da canção, comparando as "regras gramaticais" empregadas no texto da canção com as regras gramaticais em que o verbete deverá ser elaborado. Outras rubricas poderão ser inseridas, conforme adaptação da proposta.

A primeira produção será um primeiro encontro com o gênero verbete, do ponto de vista da sua realização textual. Se antes cada grupo havia se dedicado à elaboração de uma rubrica específica, agora é hora de juntar os resultados de cada grupo num primeiro esforço de visualização do verbete de enciclopédia para "cuitelinho". Para os módulos, os grupos poderão ser desfeitos, de modo que sejam trabalhadas oficinas específicas sobre cada rubrica do verbete com toda a turma.

\footnotetext{
${ }^{13}$ A proposta de publicação em ambiente virtual poderá ser orientada com vistas à publicação na própria Wikipédia, haja vista o fato de o verbete "cuitelinho", neste ambiente, apresentar pouquíssimas informações.
} 
O Módulo1 poderá abordar as principais dificuldades da expressão escrita, considerando que o objetivo da Rubrica 1 era o de contextualizar a letra da canção no quadro maior da história da Música Popular Brasileira. É interessante pensar uma abordagem que considere: a adequação dos conteúdos do texto no plano do tema proposto; a adequação da tipologia textual em relação à situação de comunicação; a adequação do planejamento e da realização do texto enquanto formalização linguística. O Módulo 2 poderá ser uma continuação do primeiro, à medida que poderá propor os mesmos objetivos de avaliação e reescrita.

Nos Módulos 3 e 4 entrarão os elementos gramaticais propriamente ditos. Entretanto, como o caminho proposto parte da observância e da descrição da gramática da letra da música, esses módulos buscarão promover um entendimento mais amplo da expressão "norma gramatical". Ao refletir acerca das "normas" subjacentes ao textoalvo do verbete, o trabalho da sequência didática propõe que o sistema linguístico não cria caoticamente no nada. Pelo contrário, aqui, se o/a professor/a cotejar, por exemplo, a explicação já referenciada em A Língua de Eulália (BAGNO, 2006), poderá enriquecer a explicação sobre a língua, destacando: a questão dos plurais e das conjugações verbais, cujas regras podem variar conforme estilo, faixa etária, região, fatores socioeconômicos, etc; o aspecto fonético-fonológico, que pode ser explorado não apenas pela escuta da música, mas também através de filmes, entrevistas gravadas, que ajudem a pensar a transformação do "lh" em "i". Por fim, outro fato que se pode trabalhar aqui diz respeito à investigação sobre a mudança linguística. Quais dessas regras verificadas na letra "Cuitelinho" se fazem presentes nos usos mais monitorados, urbanos e formais? Daí a importância da identificação dos traços graduais e descontínuos (BORTONI-RICARDO, 2004, 2005). Aqui, seria possível, inclusive, motivar uma reflexão mais detida acerca das diferentes maneiras pelas quais a letra de música "Cuitelinho" é registrada. Em Bagno (2006) e Bortoni-Ricardo (2004) a letra mantém algumas características que a versão da Wikipédia parece querer "corrigir". Por que isso se dá?

Um projeto de ensino, como a sequência didática aqui sugerida, para ser posto em prática com rigor e sistematicidade, necessitaria de tempo, planejamento e adaptação. Não bastariam cinco ou seis aulas, pois se trata de uma atividade a ser pensada e executada a longo e médio prazo. Por fim, o trabalho seria concluído com a produção final e com a publicação do verbete em ambiente virtual. Para a produção final, caberia dividir novamente a turma em grupos de modo que cada grupo pudesse retomar sua produção inicial de maneira a aperfeiçoá-la.

\section{5) Considerações finais}

Com base na discussão que a análise dos dados nos permitiu realizar, é possível, finalmente, encaminhar algumas considerações. O trabalho permitiu apontar, no quadro teórico discutido, uma gama consistente de abordagens que dão conta, com absoluta clareza e rigor científico, de subsídios fundamentais para elaboração de práticas 
pedagógicas em língua materna atentas à ampliação de competências comunicativas e sensíveis ao trabalho com a variação linguística. Carece ainda de investigação, todavia, saber em que medida esse quadro teórico é partilhado e debatido entre a classe docente, especialmente a comunidade de professores/as mais afastada dos meios acadêmicos. Além disso, embora não tenha sido possível concluir seguramente o quanto o corpus analisado corresponde à realidade da formação superior em Letras (licenciatura em Língua Portuguesa e Literatura) em âmbito nacional, nosso estudo permitiu concluir que a formação em Letras não pode prescindir de garantir ao/à futuro/a professor/a os princípios de análise linguística necessários ao trabalho com o texto. $\mathrm{O}$ estudo também permitiu concluir que manusear o instrumental de análise linguística é condição indispensável ao tratamento devido ao fenômeno da variação linguística. E que esta necessidade em nada se confunde com o recrudescimento da postura tradicional sobre o ensino da norma padrão. Pelo contrário, trata-se, conforme discussão encaminhada, de pensarmos em metodologias e práticas de ensino que possibilitem ao/à estudante se apropriar com desenvoltura da língua falada e escrita empiricamente observada em gêneros discursivos da cultura letrada e em situações variadas de monitoramento linguístico. Além disso, enfatizamos a necessidade de se pensar a norma culta a ser ensinada como uma língua viva e, por isso mesmo, cambiante, variável. Mas que essa flexibilidade obedece a regras do sistema linguístico, razão pela qual, mais uma vez, a análise linguística torna-se um imperativo.

O estudo possibilitou, ainda, apontar uma proposta de trabalho a partir da elaboração de uma sequência didática, tendo como foco o gênero verbete. Enfatizamos, na proposta de atividade, a preocupação com a necessidade de haver sistematicidade e rigor metodológico no trabalho com o gênero discursivo. Além disso, fomos guiados pelo interesse pedagógico de apresentar um estudo propositivo que, além de apontar os desafios da prática docente do/a profissional de Letras, também apontasse caminhos. Por fim, destacamos que os Estudos Linguísticos, especialmente no campo de aplicação ao ensino, têm oferecido relevantes contribuições para a construção de uma pedagogia em língua materna atenta às especificidades léxico-gramaticais do Português Brasileiro. Cabe ainda ampliar o acesso a esse conhecimento, garantindo a sua devida democratização, passo fundamental para superação do ensino normativo de língua, de que se fala há pelo menos trinta e dois anos (considerando o recorte aqui discutido, tendo como ponto de partida a publicação de $O$ texto na sala de aula).

\section{Referências}

BAGNO, M. Preconceito linguístico: o que é, como se faz. São Paulo: Edições Loyola, 1999.

Português ou brasileiro?: um convite à pesquisa. São Paulo: Parábola, 2001. 
2003.

A norma oculta: língua e poder na sociedade brasileira. São Paulo: Parábola,

A língua de Eulália: novela sociolinguística. São Paulo: Contexto, 2006.

Nada na língua é por acaso: por uma pedagogia da variação linguística. São Paulo: Parábola, 2007.

Gramática Pedagógica do Português Brasileiro. São Paulo: Parábola, 2011.

BAKHTIN, M. Estética da criação verbal. São Paulo: WMF Martins Fontes, 2010.

BATISTA, A. A. G. A avaliação dos livros didáticos: para entender o Programa Nacional do Livro Didático (PNLD). In: ROJO, R. \& BATISTA, A. A. G. (orgs.) Livro didático de língua portuguesa, letramento e cultura da escrita. Campinas: Mercado de Letras, 2003. p. 25-67.

BOPP DA SILVA, T. Estamos formando professores que conhecem a variação linguística? Uma análise acerca da importância dos dados e das teorias para o ensino de línguas. Letras \& Letras, v. 31, n. 2, p. 144-156, 2015.

BORTONI-RICARDO, S. M. Educação em língua materna: a sociolinguística na sala de aula. São Paulo: Parábola, 2004.

Nós cheguemu na escola, e agora? Sociolinguística \& educação. São Paulo: Parábola, 2005.

BRANDÃO, S. F. Um estudo variacionista sobre a lateral palatal. Letras de Hoje, v. 42, n. 3, p. 89-99, 2007.

BRASIL. MINISTÉRIO DA EDUCAÇÃO. SECRETARIA DE EDUCAÇÃO

BÁSICA. Parâmetros Curriculares Nacionais $3^{\circ}$ e $4^{\circ}$ Ciclos do Ensino Fundamental: Língua Portuguesa. Ministério da Educação. Secretaria de Educação Básica: Brasília (DF), 1998.

CÂMARA JR., J. M. Dispersos. Rio de Janeiro: Lucerna, 2004.

COSTA, S. R. Dicionário de gêneros textuais. Belo Horizonte: Autêntica, 2014.

CUITELINHO. In: WIKIPÉDIA, a enciclopédia livre. Flórida: Wikimedia Foundation, $2015 . \quad$ Disponível em: $<$ https://pt.wikipedia.org/w/index.php?title=Cuitelinho\&oldid=43697173 > . Acesso em: 6 out. 2016.

CYRINO, S. M. L. Observações sobre a mudança diacrônica no português do Brasil: objeto nulo e clíticos. In: ROBERTS, I. \& KATO, M. A. (orgs.) Português brasileiro: uma viagem diacrônica. Campinas: Editora da UNICAMP, 1996. p. 163-184. 
Elementos nulos pós-verbais no português brasileiro oral contemporâneo. In: NEVES, M. H. de M. (org.) Gramática do português falado (v. VII). Campinas: Editora da UNICAMP, 1999. p. 595-625.

DILLINGER, M. Padrões de complementação no português brasileiro. In: KATO, M. A. (org.) Gramática do português falado (v. V). Campinas: Editora da UNICAMP, 2002. p. 277-326.

DIONISIO, A. P. Variedades linguísticas: avanços e entraves. In: DIONISIO, A. P. \& BEZERRA, M. A. (orgs.) O livro didático de português: múltiplos olhares. Rio de Janeiro: Lucerna, 2005. p. 75-88.

FARACO, C. A. Norma culta brasileira: desatando alguns nós. São Paulo: Parábola, 2008.

GERALDI, J. W. O texto na sala de aula. São Paulo: Ática, 2004.

GNERRE, M. Linguagem, escrita e poder. São Paulo: Martins Fontes, 1991.

GONZÁLEZ, C. A. Variação linguística em livros didáticos para o EM. In: ZILLES, A. M. S. \& FARACO, C. A. (orgs.) Pedagogia da variação linguística: língua diversidade e ensino. São Paulo: Parábola, 2015. p. 225-245.

LIMA, R. J. Variação linguística e os livros didáticos de português. In: MARTINS, M. A., VIEIRA, S. R. \& TAVARES, M. A. (orgs.) Ensino de português e sociolinguística. São Paulo: Contexto, 2014. p. 115-131.

LUCCHESI, D. Norma linguística e realidade social. In: BAGNO, Marcos (org.) Linguística da norma. São Paulo: Loyola, 2012. p. 57-83.

NARO, A. J.; SCHERRE, M. M. P. Estabilidade e mudança linguística em tempo real: a concordância de número. In: PAIVA, M. da C. de \& DUARTE, M. E. L. (orgs.) Mudança linguística em tempo real. Rio de Janeiro: Contra Capa, 2003. p. 47-62.

NUNES, J. M. Direção de cliticização, objeto nulo e pronome tônico na posição de objeto em português brasileiro. In: ROBERTS, I. \& KATO, M. A. (orgs.) Português brasileiro: uma viagem diacrônica. Campinas: Editora da UNICAMP, 1996. p. 207222.

ROJO, R. Letramentos múltiplos, escola e inclusão social. São Paulo: Parábola Editorial, 2009.

SCHNEUWLY, B.; DOLZ, J. et al. Gêneros orais e escritos na escola. Campinas: Mercado das Letras, 2004.

SOARES, M. Alfabetização e Letramento. São Paulo: Contexto, 2014.

VIEIRA, S. R. Concordância verbal. In: VIEIRA, S. R. \& BRANDÃO, S. F (orgs.) Ensino de gramática: descrição e uso. São Paulo: Contexto, 2008. p. 85-102. 
ZABALA, A. A Prática Educativa: como ensinar. Porto Alegre: Artmed, 1998. 